\title{
A DESCONSIDERAÇÃo DA PESSOA JURÍDICA E A LEI DE LIBERDADE ECONÔMICA
}

\author{
* Lucas Naif Caluri
}

\section{Resumo:}

A Lei da Liberdade Econômica trouxe novidades significativas no mundo jurídico, em especial no instituto da desconsideração da personalidade jurídica. Há uma nova perspectiva nas relações entre os particulares, dando-se mais valor ao princípio da autonomia da vontade das partes e o viés liberal. O presente trabalho, realizado com supedâneo na revisão bibliográfica da doutrina, enfrentar ${ }^{1} a ́$ as novidades legislativas. O estudo traçará as novas linhas oferecidas pelo legislador, analisando-se detidamente o artigo 50 do Código Civil e a maior proteção aos negócios jurídicos firmados entre particulares.

\section{Palavras-chave:}

Desconsideração; Personalidade jurídica; Liberdade Econômica.

\section{THE DISCONSIDERATION OF LEGAL ENTITIES AND THE LAW OF ECONOMIC FREEDOM}

\begin{abstract}
:
The Law on Economic Freedom brought significant news in the legal world, especially in the institute of disregarding legal personality. There is a new perspective on relations between individuals, giving more value to the principle of autonomy of the parties' will and the more liberal bias. The present work, carried out with a superintendent in the bibliographic review of the doctrine, will face the legislative novelties. The study will outline the new lines offered by the legislator, analyzing in detail Article 50 of the Private Codification and the greater protection for the legal deals signed between private individuals.
\end{abstract}

\footnotetext{
* Doutorando em Direito pela Universidade Mackenzie de São Paulo (2020). Mestre em Direito pela Universidade Metodista de Piracicaba (2006). Especialista pela Pontifícia Universidade Católica de Campinas (2002). Graduado em Direito pela Faculdade de Direito de São Carlos (1997). Professor da PUC-Campinas. Professor do Centro Universitário Salesiano de São Paulo. Professor da FACAMP (Faculdades de Campinas). Endereço postal: Rua Coelho Neto, 331, ap. 101, Vila Itapura, Campinas-SP, Cep 13023-020. Rua Endereço eletrônico: lucasnaifcaluri@ aasp.org.br
} 


\section{Keywords:}

Disregard; legal personality; Economic freedom.

\section{INTRODUÇÃO}

Inúmeras mudanças estão sendo vivenciadas por todos, tanto pelo impacto causado pela pandemia global do Covid-19, quanto pelas novas adequações econômicas/empresariais/empregatícias globais, causadas, principalmente, pelos novos modelos de negócios, em especial pela conexão global de milhões de pessoas nas redes mundiais de computadores, efeitos incontestes decorrentes da globalização. O novo mundo é um marco revolucionário, causado pela denominada revolução 4.0.

A Lei 13.874 de 2019, denominada Lei da Liberdade Econômica, tentou privilegiar imensuravelmente a prática e a segurança de atos privados, com a mínima ingerência Estatal nos contratos e negócios entre particulares, com caráter liberal.

A referida lei trouxe inúmeras mudanças para o Código Civil, em especial no que tange aos institutos da desconsideração da personalidade jurídica e na teoria geral dos contratos, modificando artigos que traziam normas privadas de conceito aberto, - a exemplo do artigo 113 da Codificação Privada², para uma nova sistemática, conforme se elaborará adiante.

Um novo conceito de pensamento vem sendo desenhado pelo legislador, com aplicação direta nas relações privadas, como a prevalência do princípio da autonomia privada em face da supremacia da ordem pública. Vê-se um viés mais liberal em detrimento do social.

\footnotetext{
${ }^{2}$ A Lei 10.406, de 10.01.2002, aponta em seu art. 113 que "os negócios jurídicos devem ser interpretados conforme a boa-fé e os usos do lugar de sua celebração.

$\S 1^{\circ} \mathrm{A}$ interpretação do negócio jurídico deve lhe atribuir o sentido que:

I - for confirmado pelo comportamento das partes posterior à celebração do negócio;

II - corresponder aos usos, costumes e práticas do mercado relativas ao tipo de negócio;

III - corresponder à boa-fé;

IV - for mais benéfico à parte que não redigiu o dispositivo, se identificável; e

V - corresponder a qual seria a razoável negociação das partes sobre a questão discutida, inferida das demais disposições do negócio e da racionalidade econômica das partes, consideradas as informações disponíveis no momento de sua celebração.

$\S 2^{\circ}$ As partes poderão livremente pactuar regras de interpretação, de preenchimento de lacunas e de integração dos negócios jurídicos diversas daquelas previstas em lei”.
} 
A Lei de Liberdade Econômica acrescentou o artigo 49-A e alterou o artigo 50 da Codificação Privada pertinente ao instituto da desconsideração da personalidade jurídica. $\mathrm{Na}$ mesma linha de pensamento, isto é, corroborando aos novos intuitos legislativos, a Lei 13.874 de 2019 também incluiu o artigo 421-A e alterou o artigo 421 do Código Civil, no tocante a teoria geral dos contratos.

O presente artigo comentará as mudanças trazidas pela Lei de Liberdade Econômica no instituto da desconsideração da personalidade jurídica, sua nova mentalidade prática e a força do pactuado entre as partes, considerando o novo histórico legislativo liberal.

\section{DAS MUDANÇAS NO INSTITUTO DA DESCONSIDERAÇÃO DA PERSONALIDADE JURÍDICA}

As novas diretrizes da desconsideração da personalidade jurídica foram iniciadas com a Medida Provisória 881 de 2019, que elencava diversas mudanças no ramo trabalhista, bem como no instituto da desconsideração da personalidade jurídica, inclusive, trouxe, na época de sua vigência, um novo requisito, retirado pela Lei 13.874 de 2020, que era o elemento doloso e intencional para prejuízo de terceiros e futuros credores.

O dolo não mais se encontra vigente como um requisito para a desconsideração e consequentemente responsabilização dos sócios e gestores da pessoa jurídica. Basta que ocorra a ação culposa de abuso da personalidade jurídica, calçada no desvio de finalidade ou confusão patrimonial e outras mudanças a serem aqui mencionadas, para que seja efetivada a desconsideração da personalidade jurídica.

A primeira mudança no instituto da desconsideração da personalidade jurídica foi a inclusão do artigo 49-A no Código Civil $^{3}$.

\footnotetext{
${ }^{3}$ A Lei 10.406, de 10.01.2002, destaca em seu artigo 49-A, que "Art. 49-A. A pessoa jurídica não se confunde com os seus sócios, associados, instituidores ou administradores. (Incluído pela Lei nº 13.874, de 2019)

Parágrafo único. A autonomia patrimonial das pessoas jurídicas é um instrumento lícito de alocação e segregação de riscos, estabelecido pela lei com a finalidade de estimular empreendimentos, para a geração de empregos, tributo, renda e inovação em benefício de todos".
} 
O parágrafo único do artigo 49-A do Código Civil deixa clara a nova linha de pensamento e de segmento, qual seja, a linha liberal na prática dos atos particulares. Ora, o legislador deixou assente a sua intenção na própria redação do citado artigo: "a autonomia patrimonial das pessoas jurídicas é um instrumento lícito de alocação e segregação de riscos, estabelecido pela lei com a finalidade de estimular empreendimentos, para a geração de empregos, tributo, renda e inovação em benefício de todos”. Isto é, o legislador enaltece que o patrimônio pessoal é protegido, a fim de dar segurança aos particulares, giro na economia e incentivo para a criação de pessoas jurídicas.

Assim, com as novas alterações advindas da Lei da Liberdade Econômica, deu-se maior liberdade e segurança para a pessoa jurídica, isto é, o intuito da Lei foi fortalecer o instituto da pessoa jurídica, dando-se maior segurança aos negócios firmados.

Arnoldo Wald (2009, p. 185) tenta explicitar que o conceito da pessoa jurídica

não se firmou definitivamente no direito romano, reconhecendo-se, todavia, personalidade e capacidade jurídica ao Estado, aos municípios, ao Fisco e, no campo do direito privado, a certas sociedades e fundações. No direito pósclássico, as igrejas, mosteiros, hospícios, hospitais, estabelecimentos de beneficência constituíam verdadeiras fundações denominadas corpora (corpos) e, segundo o direito romano, eram equiparadas às pessoas físicas, como também o era a herança jacente, ou seja, aquela que ainda não fora adjudicada aos herdeiros. Encontram-se no Digesto os princípios básicos que ainda hoje regem as pessoas jurídicas, distinguindo-se, já naquela época, o patrimônio social do patrimônio individual dos membros da sociedade (Digesto, 4.4.7, 1). Devemos salientar, todavia, que, para o direito romano, a personalidade jurídica dependia de reconhecimento pelo Estado, que assim podia atribuir direitos e obrigações a certo grupos sociais. Cabe salientar que a palavra persona, no direito romano, significava, inicialmente, a máscara do autor, mediante a qual saía o som de sua voz, como indica a etimologia: per sonare. Em seguida, pessoa passou a ser o sujeito de direitos e obrigações reconhecido pelo direito.

As pessoas jurídicas "são entidades a que a lei empresta personalidade, isto é, são seres que atuam na vida jurídica, com personalidade diversa da dos indivíduos que os compõem, capazes de serem sujeitos de direitos e obrigações na ordem civil” (RODRIGUES, 2005, p. 86).

No direito romano a pessoa jurídica não existia (MONTEIRO, 2009, p. 131) "na primeira fase do Império Romano, conheciam-se, entretanto, certas associações de interesses 
públicos, como universitates, sodalitates, corpora e collegia. No direito Justiniano, enriqueceu-se a pessoa jurídica com o acréscimo das fundações".

Sílvio de Salvo Venosa (2015, p. 245) aponta a dificuldade na denominação da pessoa jurídica:

Não é unânime na doutrina e nas várias legislações a denominação pessoa jurídica. Essa é a denominação de nosso Código e também do Código alemão. $\mathrm{Na}$ França, usa-se a expressão 'pessoas morais'. Na verdade, a denominação por nós utilizada tem a vantagem de realçar o aspecto jurídico, o que nos interessa. 'Pessoa coletiva' é como denomina o Direito português, realçando mais o aspecto externo do instituto; enfatiza as pessoas jurídicas constituídas de indivíduos, mas deixa de fora aquelas pessoas jurídicas constituídas fundamentalmente de patrimônio, que são as fundações.

A pessoa jurídica, para Roberto Senise Lisboa (2009, p. 231)

é a entidade diversa da pessoa natural (por isso é chamada de entidade moral), solenemente constituída pela vontade de outras pessoas, físicas ou jurídicas, com personalidade e patrimônio próprios e distintos dos de seus constituintes, e determinada finalidade prevista na sua ata constitutiva.

De acordo com Arnaldo Rizzardo (2008, p. 247) a pessoa jurídica tem a sua personalidade autônoma dos entes que a compõem, fortalecendo o princípio da autonomia da vontade das partes que "de modo que várias pessoas naturais se congregam e formam uma unidade, dando origem a um novo ser, que passa a ter sua personalidade completamente separada me diferente daquela dos indivíduos que a constituíram”.

Na mesma linha de pensamento quanto a autonomia de personalidade, Pablo Stolze e Rodolfo Pamplona Filho (2011, p. 224) afirmam, “assim, nascendo como contingência do fato associativo, o direito confere personalidade jurídica a esse grupo, viabilizando a sua atuação autônoma e funcional, com personalidade própria, com visas à realização de seus objetivos”.

De forma mais incisiva quanto a autonomia de vontades da pessoa jurídica, Fábio Ulhoa Coelho (2014, p. 256)

A mais relevante consequência dessa conceituação das pessoas jurídicas é sintetizada no princípio da autonomia. As pessoas jurídicas não se confundem com as pessoas que a integram - dizia preceito do antigo Código Civil. Em outros termos, a pessoa jurídica e cada um dos seus membros são sujeitos de direito autônomos, distintos, inconfundíveis. 
Quanto à autonomia de personalidades entre a pessoa natural e da pessoa jurídica, leciona Carlos Roberto Gonçalves (2012, p. 216)

A pessoa jurídica é, portanto, proveniente desse fenômeno histórico e social. Consiste num conjunto de pessoas ou de bens, dotado de personalidade jurídica própria e constituído na forma da lei, para a consecução de fins comuns. Pode-se afirmar, pois, que pessoas jurídicas são entidades a que a lei confere personalidade, capacitando-as a serem sujeitos de direitos e obrigações. A sua principal característica é a de que atuam na vida jurídica com personalidade diversa da dos indivíduos que a compõem (CC, art.50, a contrario sensu, e art. 1.024)

Quanto à interpretação restritiva e a aplicação limitada da desconsideração da personalidade, considerando os novos parâmetros expostos na Lei de Liberdade Econômica, expõe Maria Helena Diniz (2008, p. 60)

Só se aplica a desconsideração da personalidade jurídica quando houver a prática de ato irregular, e limitadamente aos administradores ou sócios que nela hajam incorrido (Enunciado n.7, aprovado na Jornada de Direito Civil, promovida em 2002 pelo Conselho da Justiça Federal). E, pelo seu Enunciado n.51, a disregard doctrine fica positivada no novo Código, e os parâmetros existentes nos microssistemas legais e na construção doutrinária serão mantidos. Pelo seu Enunciado n. 146 (Aprovado na Jornada de Direito Civil de 2004): "Nas relações civis, interpretam-se restritivamente os parâmetros de desconsideração da personalidade jurídica previstos no art. 50 (desvio de finalidade social ou confusão patrimonial).

Ora, considerando toda a problemática atual, isto é, mudanças industriais, em especial no que tange as novas modalidades de trabalho e a necessidade de inovação das pessoas, nada mais razoável que privilegiar a inovação, através da segurança na constituição de pessoas jurídicas, com a proteção e a separação dos patrimônios das pessoas que a constituem com o patrimônio da pessoa jurídica.

Conforme visto, a Lei assegura a autonomia da pessoa jurídica para a prática dos atos civis e negociais, protegendo as pessoas naturais que a compõem (sócios, administradores, fundadores, gestores), sendo a responsabilização por débitos, via de regra e agora ainda mais presente no artigo 49-A do Código Civil, dentro dos limites do capital social da pessoa jurídica.

Referendando a maior segurança nos negócios entre particulares e dando-se força aos negócios firmados pelas pessoas jurídicas, isto é, separando o patrimônio pessoal dos bens da 
empresa, outras novidades dignas de reflexões são as novas diretrizes e disposições elencadas na teoria geral dos contratos, a exemplo dos artigos 421; 421-A do Código Civil.

Dispõe o artigo 421 do Código Civil que: a liberdade contratual será exercida nos limites da função social do contrato. Parágrafo único. Nas relações contratuais privadas, prevalecerão o princípio da intervenção mínima e a excepcionalidade da revisão contratual.

As mudanças na desconsideração da personalidade jurídica devem ser analisadas em conjunto com as novas diretrizes contratuais, em especial na maior segurança dos negócios jurídicos firmados entre os particulares, conforme nova diretriz do parágrafo único do artigo 421 do Código Civil. O intuito da Lei é claro, dar segurança aos negócios firmados, girar a economia e incentivar a prática de atos civil e negociais, protegendo, inclusive, as pessoas jurídicas.

Importante asseverar que a nova diretriz para a aplicação da desconsideração da personalidade jurídica leva-se em conta critérios objetivos de investigação, tendo em vista o que dispõe o artigo 49-A e $\$ 2^{\circ}$ do artigo 50 do Código Civil. Aliás, as mudanças aqui elencadas, conversam com o enunciado 23 da I Jornada de Direito Comercial: "em contratos empresariais, é lícito às partes contratantes estabelecer parâmetros objetivos para a interpretação dos requisitos de revisão e/ou resolução do pacto contratual”.

Imperioso mencionar que a Codificação Privada, com as alterações trazidas pela Lei 13.874 de 2019, deixou assente que a regra geral para a responsabilização por dívidas das pessoas jurídicas é determinada na sua própria pessoa, isto é, somente em casos excepcionais e que o patrimônio dos sócios será afetado e desde que presentes os requisitos para essa responsabilização.

As alterações elencadas se conversam com o Novo Código de Processo Civil, haja vista o instituto processual próprio da desconsideração da personalidade civil, previsto no artigo 133 e seguintes do NCPC.

Sobre a pertinência da temática, e escrevendo sobre os impactos da Lei da Liberdade Econômica nas relações privadas, Nelson Rosenvald (2020, p.11), em artigo publicado na Revista de Direito, pondera que 
Não há qualquer exagero por parte do Legislador ou atuação em contrariedade à Constituição Federal, pois não atuou o mesmo afastando a função social das relações privadas. Muito menos estabeleceu uma guinada de orientação. Pelo contrário, ele afinou os controles, definiu com clareza o fundamento de orientação, não deixando, agora, qualquer dúvida da funcionalização econômica, e firmando que a racionalidade econômica deve ser ponderada pelo intérprete e aplicador do direito. Não há inconstitucionalidade quando o legislador infraconstitucional assume espaço que lhe fora deixado pelo Constituinte, definido com precisão direitos ou regras estabelecidas genericamente por este.

Outra mudança digna de nota é a nova redação do artigo 50 da Codificação Privada e seus parágrafos ${ }^{4}$, uma vez que traz a ideia de conceitos objetivos na desconsideração da personalidade jurídica, retirando um pouco do subjetivismo dos casos práticos.

Um bom exemplo de atos que possam desencadear a desconsideração da personalidade jurídica é previsto no inciso II, do $\$ 2^{\circ}$, do artigo 50 do Código Civil: transferência de ativos ou de passivos sem efetivas contraprestações, exceto os de valor proporcionalmente insignificante. Veja que a Lei traz situações hipotéticas objetivas, dandose maior segurança jurídica as partes.

A mudança do artigo 50 do Código Civil deixou clara a intenção do legislador quanto a necessidade de demonstração do benefício direto ou indireto do sócio da pessoa jurídica.

4 A Lei 10.406, de 10.01.2002, destaca em seu art. 50, que "em caso de abuso da personalidade jurídica, caracterizado pelo desvio de finalidade ou pela confusão patrimonial, pode o juiz, a requerimento da parte, ou do Ministério Público quando lhe couber intervir no processo, desconsiderá-la para que os efeitos de certas e determinadas relações de obrigações sejam estendidos aos bens particulares de administradores ou de sócios da pessoa jurídica beneficiados direta ou indiretamente pelo abuso. (Redação dada pela Lei n ${ }^{\circ} 13.874$, de 2019)

$\S 1^{\circ}$ Para os fins do disposto neste artigo, desvio de finalidade é a utilização da pessoa jurídica com o propósito de lesar credores e para a prática de atos ilícitos de qualquer natureza. (Incluído pela Lei n ${ }^{\circ} 13.874$, de 2019)

$\S 2^{\circ}$ Entende-se por confusão patrimonial a ausência de separação de fato entre os patrimônios, caracterizada por: (Incluído pela Lei n ${ }^{\circ} 13.874$, de 2019)

I - cumprimento repetitivo pela sociedade de obrigações do sócio ou do administrador ou vice-versa; $\underline{\text { (Incluído }}$ pela Lei no 13.874 , de 2019)

II - transferência de ativos ou de passivos sem efetivas contraprestações, exceto os de valor proporcionalmente insignificante; e (Incluído pela Lei no 13.874, de 2019)

III - outros atos de descumprimento da autonomia patrimonial. (Incluído pela Lei $\mathrm{n}^{\circ} 13.874$, de 2019)

$\S 3^{\circ} \mathrm{O}$ disposto no caput e nos $\S \S 1^{\circ}$ e $2^{\circ}$ deste artigo também se aplica à extensão das obrigações de sócios ou de administradores à pessoa jurídica. (Incluído pela Lei no 13.874, de 2019)

$\S 4^{\circ}$ A mera existência de grupo econômico sem a presença dos requisitos de que trata o caput deste artigo não autoriza a desconsideração da personalidade da pessoa jurídica. (Incluído pela Lei $n^{\circ} 13.874$, de 2019)

$\S 5^{\circ}$ Não constitui desvio de finalidade a mera expansão ou a alteração da finalidade original da atividade econômica específica da pessoa jurídica". (Incluído pela Lei n ${ }^{\circ} 13.874$, de 2019) 
Isto é, conforme declinado na nova redação do artigo 50, parte final, o legislador é enfático em mencionar "beneficiados direta ou indiretamente pelo abuso". Denota-se que a redação antiga do artigo 50 do Código Civil nada mencionava acerca de benefícios com o abuso na gestão. Analisemos abaixo a redação anterior com a atual a fim de referendar o que aqui se propõe (Tabela 1).

Tabela 1 - quadro comparativo da redação do artigo 50 Código Civil (Lei 13.406/20) e a nova redação dada pela Lei de Liberdade Econômica (Lei 13.874/19)

\begin{tabular}{|c|c|}
\hline Artigo 50 do C.C antes da Lei 13.874/19: & Redação atual do artigo 50 do C.C: \\
\hline $\begin{array}{l}\text { Em caso de abuso da personalidade } \\
\text { jurídica, caracterizado pelo desvio de } \\
\text { finalidade, ou pela confusão patrimonial, } \\
\text { pode o juiz decidir, a requerimento da } \\
\text { parte, ou do Ministério Público quando } \\
\text { lhe couber intervir no processo, que os } \\
\text { efeitos de certas e determinadas relações } \\
\text { de obrigações sejam estendidos aos bens } \\
\text { particulares dos administradores ou sócios } \\
\text { da pessoa jurídica. }\end{array}$ & $\begin{array}{l}\text { Em caso de abuso da personalidade jurídica, } \\
\text { caracterizado pelo desvio de finalidade ou pela } \\
\text { confusão patrimonial, pode o juiz, a } \\
\text { requerimento da parte, ou do Ministério Público } \\
\text { quando lhe couber intervir no processo, } \\
\text { desconsiderá-la para que os efeitos de certas e } \\
\text { determinadas relações de obrigações sejam } \\
\text { estendidos aos bens particulares de } \\
\text { administradores ou de sócios da pessoa jurídica } \\
\text { beneficiados direta ou indiretamente pelo } \\
\text { abuso. }\end{array}$ \\
\hline
\end{tabular}

Fonte: Elaboração pelo próprio autor, (2020).

Vê-se que ainda é vigente para a caracterização da desconsideração da personalidade civil o abuso na personalidade de pessoa jurídica, caracterizada pelos requisitos subjetivos do desvio de finalidade e a confusão patrimonial, com um acréscimo de suma importância imposta pela Lei da Liberdade Econômica, qual seja, a prova do benefício direto e ou indireto nas hipóteses de abuso.

O Código Civil, conforme é sabido, sempre aplicou a teoria maior da desconsideração, isto é, sempre exigiu a comprovação subjetiva de abuso da personalidade, 
porém, antes da Lei de Liberdade Econômica, era silente quanto a benefícios diretos ou indiretos.

Deve-se sempre ter em mente que o artigo retro citado deve ser lido e interpretado em harmonia com o artigo 187 do Código Civil que estipula: "Também comete ato ilícito o titular de um direito que, ao exercê-lo, excede manifestamente os limites impostos pelo seu fim econômico ou social, pela boa-fé ou pelos bons costumes".

Ora, o legislador não deu a separação de patrimônios irrestritas, haja vista que ocorrendo o mal uso da pessoa jurídica, calcada sempre na teoria do abuso de direito, poderá ser responsabilizada mediante o ataque pessoal dos bens dos sócios. Porém, o que pretendeu a Lei de Liberdade Econômica foi dar maior segurança nas relações privadas, a fim de se adequar aos novos modelos de negócios, calcada, a meu ver, na inovação.

A mudança e o acréscimo em questão denotam claramente o intuito do legislador em proteger, com mais profundidade, a separação dos bens dos sócios da pessoa jurídica com os bens e patrimônio da própria pessoa jurídica.

O acréscimo legal foi no mesmo sentido do Enunciado 7, da I Jornada de Direito Civil $^{5}$, que dispunha sobre a averiguação, no caso concreto, de ato irregular no manejo da pessoa jurídica e a limitação da responsabilidade do causador do abuso; "só se aplica a desconsideração da personalidade jurídica quando houver a prática de ato irregular e, limitadamente, aos administradores ou sócios que nela hajam incorrido”.

Conforme citado no início, as mudanças no instituto da desconsideração da personalidade surgiram, incialmente, com a Medida Provisória 881 de 2019, e trazia como requisito fundamental para a sua configuração a ação dolosa com o propósito de lesar terceiros/credores, conforme se depreende do $\S 1^{\circ}$, não convertido em Lei: " $\S 1^{\circ}$ Para fins do disposto neste artigo, desvio de finalidade é a utilização dolosa da pessoa jurídica com o propósito de lesar credores e para a prática de atos ilícitos de qualquer natureza”.

5JUSTIÇA FEDERAL. Conselho da Justiça Federal. Disponível em: https://www.cjf.jus.br/cjf/corregedoria-da-justica-federal/centro-de-estudos-judiciarios-1/publicacoes1/jornadas-cej/EnunciadosAprovados-Jornadas-1345.pdf Acesso em: 11 set. 2020. 
Assim, agiu bem o legislador em não acatar a ação dolosa para a configuração, no caso concreto, dos requisitos da desconsideração da personalidade jurídica, haja vista a dificuldade de se provar eventual abuso e fraude.

O $\S 1^{\circ}$ do artigo 50, do Código Civil, acrescentado também pela Lei 13.874 de 2019, prescreve como desvio de finalidade a utilização da pessoa jurídica com o propósito de lesar credores e para a prática de atos ilícitos de qualquer natureza. Aqui, é importante destacar que o desvio de finalidade também pode ocorrer de forma reversa, ao contrário, a denominada desconsideração da personalidade jurídica inversa, que nada mais é que a utilização da pessoa jurídica para fraudar negócios jurídicos particulares dos sócios que a compõem.

A referida desconsideração inversa também tem ampla aceitação e aplicação na área de família e sucessões, inclusive quanto a fraudes em meações de bens do casamento/união estável, quando o sócio tenta utilizar da pessoa jurídica para fraudar compra de imóveis/bens em nome da pessoa jurídica.

Acerca do diálogo entre o Código Civil e o Código de Processo Civil, ensina o processualista Fredie Didier Junior (2015, p. 514) “corretamente, O CPC não cuidou das hipóteses de desconsideração, que serão definidas em lei específica (art. 133,§ $1^{\circ}, \mathrm{CPC}$ ). O CPC apenas regula o modo de aplicar-se a sanção da desconsideração da personalidade jurídica no processo".

Ou seja, a Codificação Processual trouxe os meios para fazer valer as hipóteses de cabimento da desconsideração, sendo o Código Civil, em especial, as hipóteses previstas nos artigos 49-A e 50 o parâmetro de incidência da desconsideração.

Foi em decorrência da aceitação doutrinária e jurisprudencial que a desconsideração inversa da personalidade jurídica ganhou um dispositivo no Código de Processo Civil, especificamente no $\S 2^{\circ}$, do art. $133 .^{6}$

\footnotetext{
${ }^{6}$ A Lei 13.105, de 16.03.2015, aponta em seu art 133, que “o incidente de desconsideração da personalidade jurídica será instaurado a pedido da parte ou do Ministério Público, quando lhe couber intervir no processo. $\S 1^{\circ}$ O pedido de desconsideração da personalidade jurídica observará os pressupostos previstos em lei. $\S 2^{\circ}$ Aplica-se o disposto neste Capítulo à hipótese de desconsideração inversa da personalidade jurídica”.
} 
O parágrafo segundo do art. 50, do Código Civil, acrescentado também pela Lei 13.874 de 2019, elencou algumas situações como passíveis de aferimento no que tange a confusão patrimonial dos sócios com a pessoa jurídica, a saber: $\S 2^{\circ}$ Entende-se por confusão patrimonial a ausência de separação de fato entre os patrimônios, caracterizada por: I cumprimento repetitivo pela sociedade de obrigações do sócio ou do administrador ou viceversa; II - transferência de ativos ou de passivos sem efetivas contraprestações, exceto os de valor proporcionalmente insignificante; e III - outros atos de descumprimento da autonomia patrimonial.

Vê-se que o inciso III do $\S 2^{\circ}$, do art. 50 do CC é enfático em deixar a questão aberta, isto é, em não taxar todas as hipóteses de confusão patrimonial, tratando de norma exemplificativa. A inovação aqui é digna de nota, uma vez que traz algumas situações de ordem objetiva para a configuração da confusão patrimonial.

Quanto à inclusão do $\S 3^{\circ}$, do art. 50 do C.C, vê-se um diálogo de fontes, uma vez que, conforme aqui já defendido, as causas de abuso da personalidade jurídica também podem ocorrer inversamente, interpretando o $\$ 3^{\circ}$, do art. 50, do CC, em conjunto com $\S 2^{\circ}$ do artigo 133, do NCPC.

Quanto à novidade legislativa elencada no $\S 4^{\circ}$, do artigo 50, alguns comentários são pertinentes. $\mathrm{O} \S 4^{\circ}$, do artigo 50, do CC, deve ser analisado em conjunto com o artigo $2^{\circ}$, $\S 3^{\circ}$, da CLT. (Tabela 2)

Tabela 2 - quadro comparativo da nova redação do art. 50 Código Civil dada pela Lei de Liberdade Econômica (Lei 13.874/19) e art. 2, § 3º , da CLT (Lei 13467/17)

\begin{tabular}{|c|c|}
\hline Art. $50, \S 4^{\circ}, \mathrm{CC}$ : & Art. $2, \S 3^{\circ}$, da CLT: \\
\hline $\begin{array}{l}\text { A mera existência de grupo econômico } \\
\text { sem a presença dos requisitos de que trata } \\
\text { o caput deste artigo não autoriza a } \\
\text { desconsideração da personalidade da } \\
\text { pessoa jurídica. }\end{array}$ & $\begin{array}{l}\text { Não caracteriza grupo econômico a mera } \\
\text { identidade de sócios, sendo necessárias, para a } \\
\text { configuração do grupo, a demonstração do } \\
\text { interesse integrado, a efetiva comunhão de } \\
\text { interesses e a atuação conjunta das empresas } \\
\text { dele integrantes. }\end{array}$ \\
\hline
\end{tabular}

Fonte: Elaboração do próprio autor, (2020). 
Ambos os artigos surgiram com o novo modelo liberal, sendo a mudança do Código Civil, advinda inicialmente da Medida Provisória 881, convertida na Lei de Liberdade Econômica $n^{\circ} 13874$ de 2019 e a mudança na CLT, advinda da Medida Provisória 808 de 2017, convertida na Lei da Reforma da CLT n ${ }^{\circ} 13.467$ de 2017. Ora, ambas as leis são pautadas no princípio da liberdade contratual, novo vetor dos negócios jurídicos particulares.

Conforme se pode notar, a configuração, no âmbito laboral, de grupo econômico, após a reforma da CLT, tornou-se mais dificultosa, ou seja, a mera identidade de sócios não será apta a ensejar, de forma automática, a configuração de grupo econômico de empresas. No mesmo sentido o Código Civil, que deixou claro que a mera existência de grupo econômico sem a presença dos requisitos de que trata o caput deste artigo não autoriza a desconsideração da personalidade jurídica.

Por fim, quanto ao $\S 5^{\circ}$ do art. 50, do C.C, dispõe que não constitui desvio de finalidade a mera expansão ou a alteração da finalidade original da atividade econômica específica da pessoa jurídica. Segundo o doutrinador Flávio Tartuce (2020, p. 163), o referido parágrafo não deveria ter sido acrescentado:

Lamenta-se a manutenção a respeito da alteração da finalidade original, que deveria ter sido retirada do texto de conversão, o que foi proposto pelo Senador Pacheco, por meio da Emenda 173. Cite-se o exemplo de uma fundação que pode ter a sua autonomia desconsiderada com o fim de responsabilização dos seus administradores, caso altere a sua finalidade inicial com o objetivo de se desviar de seus fins nobres, constantes do art. 62, parágrafo único, do Código Civil.

Denota-se que a Lei de Liberdade Econômica inovou quanto ao tema da desconsideração da personalidade jurídica, trazendo novos institutos e vários parágrafos para o artigo 50 do Código Civil.

É nítido o intuito legislativo aqui, isto é, dá ao instituto da desconsideração da personalidade jurídica um viés mais liberal, com a proteção do patrimônio pessoal das pessoas que compõem a pessoa jurídica, dificultando a sua desconsideração de forma desmedida.

Um problema sempre presente diz respeito a desconsideração da personalidade jurídica disciplinada em outros sistemas jurídicos, em especial no Código de Defesa do Consumidor e no âmbito das relações de emprego, isto é, nos processos que correm perante a Justiça do Trabalho, prejudicando sócios que sequer fizeram parte de qualquer ato irregular. 
Nesses dois âmbitos, a aplicação da desconsideração da personalidade jurídica é calcada na teoria menor, aquela que somente exige a presença do prejuízo ao credor para a sua efetivação.

A teoria menor é prevista no $\S 5^{\circ}$, do art. 28 do Código de Defesa e Proteção do Consumidor ${ }^{7}$.

Na prática da Justiça do Trabalho, é comum encontrar decisões desarrazoáveis quanto a sócios que nunca fizeram parte ou administraram a pessoa jurídica, sendo responsabilizados por dívidas dos credores, em razão da desconsideração excessiva de outrora. A pergunta que fica é, será que a Justiça do Trabalho aplicará o novo instituto da desconsideração da pessoa jurídica, em especial obedecendo os artigos 49-A e 50 do Código Civil?

\section{CONSIDERAÇÕES FINAIS}

São notórias as mudanças legislativas advindas nos últimos anos: Medida Provisória 881, convertida na Lei de Liberdade Econômica $\mathrm{n}^{\circ} 13.874$ de 2019; mudança na CLT, advinda da Medida Provisória 808 de 2017, convertida na Lei da Reforma da CLT n ${ }^{\circ} 13.467$ de 2017; mudanças dos artigos 50, 113, 421 e parágrafos, inclusão do artigo 421-A do Código Civil.

É preciso ter em mente que a Lei de Liberdade Econômica - como o próprio nome sugere - tem a finalidade de chancelar o pactuado em prejuízo do legislado, com a mesma diretriz imposta pela Reforma da CLT, a título de exemplo, quanto à prevalência do negociado em detrimento do legislado (art. 611-A da CLT incluído pela Reforma da CLT Lei 13.467 de 2017).

\footnotetext{
7 De acordo com a Lei 8.078, de 11.09.1990, em seu art. 28 aponta que o "juiz poderá desconsiderar a personalidade jurídica da sociedade quando, em detrimento do consumidor, houver abuso de direito, excesso de poder, infração da lei, fato ou ato ilícito ou violação dos estatutos ou contrato social. A desconsideração também será efetivada quando houver falência, estado de insolvência, encerramento ou inatividade da pessoa jurídica provocados por má administração. $\S 5^{\circ}$ Também poderá ser desconsiderada a pessoa jurídica sempre que sua personalidade for, de alguma forma, obstáculo ao ressarcimento de prejuízos causados aos consumidores”.
} 
Agora temos de forma inequívoca a intenção do legislador de uma "menor intervenção nos contratos paritários" civis ou empresariais. Ademais, conforme se viu, há uma proteção mais sólida quanto a desconsideração da personalidade jurídica. Com efeito, a Lei da Liberdade Econômica procura valorizar a autonomia privada (princípio da obrigatoriedade, imutabilidade, pacta sunt servanda etc).

Desse modo, andou bem a Lei de Liberdade Econômica, na sua parte final, em determinar o benefício direta ou indireto do abuso daquele sócio específico. Andou bem também em trazer situações objetivas que desencadeiam a desconsideração da personalidade jurídica, o que denota maior segurança jurídica.

Em razão das novas mudanças traçadas pela Lei de Liberdade Econômica, é imperioso que o intérprete e em especial os aplicadores e operadores do direito averiguem, no caso prático, as novas mudanças de mentalidade quanto a temática, uma vez que foram grandes as transformações do artigo 50 do Código Civil.

Em reforço ao aqui mencionado e considerando a metamorfose de mentalidade, deve-se ter em mente as demais mudanças legislativas, tais como o Novo Incidente de Desconsideração previsto no Código de Processo Civil, e, via de consequência, o fortalecimento do princípio da autonomia privada das partes.

Em suma, a nova desconsideração da personalidade jurídica trouxe novos mecanismos para a sua incidência, protegendo, com maior segurança, o patrimônio dos sócios e administradores, tudo em razão da nova mentalidade e o novo viés liberal dos negócios jurídicos, isto é, dando maior importância e segurança ao princípio da autonomia da vontade das partes.

\section{REFERÊNCIAS BIBLIOGRÁFICAS}

BRASIL. Lei 8.078/90, de 11 de setembro de 1990. Institui sobre a proteção do consumidor e dá outras providências. Brasília, 1990. Disponível em http://www.planalto.gov.br/ccivil_03/leis/18078compilado.htm Acesso em: 11 set. 2020. 
BRASIL. Lei 10.406, de 10 de janeiro de 2002. Institui o Código Civil. Brasília, 2002.

Disponível em: http://www.planalto.gov.br/ccivil_03/leis/2002/L10406compilada.htm Acesso em: 11 set. 2020 .

BRASIL. Lei 13.105, de 16 de março de 2015. Institui o Código de Processo Civil. Brasília, 2015. Disponível em: http://www.planalto.gov.br/ccivil 03/ ato2015-

2018/2015/lei/113105.htm Acesso em: 11 set. 2020.

BRASIL. Lei 13.874, de 20 de setembro de 2019. Institui a Declaração de Direitos de Liberdade Econômica; estabelece garantias de livre mercado. Brasília, 2019. Disponível em: http://www.planalto.gov.br/ccivil_03/_ato2019-2022/2019/lei/L13874.htm Acesso em: 11 set. 2020 .

COELHO, Fábio Ulhoa. Curso de Direito Civil. Parte Geral. 7. ed. São Paulo: Saraiva, 2014. $256 \mathrm{p}$.

DINIZ, Maria Helena; FIUZA, Ricardo (Org.); SILVA, Regina Beatriz Tavares (Org.).

Código Civil Comentado. 6. ed. São Paulo: Saraiva, 2008. 60 p.

GAGLIANO, Pablo Stolze; FILHO, Rodolfo Pamplona. Novo Curso de Direito Civil. 13. ed. São Paulo: Saraiva, 2011. 224 p.

GONÇALVES, Carlos Roberto. Direito Civil Brasileiro. Parte Geral. 10. ed. São Paulo: Saraiva, 2012. 216 p.

JUNIOR, Fredie Didier. Curso de Direito Processual Civil. 17. ed. Salvador: JusPodivm, 2015. 514 p.

JUSTIÇA FEDERAL. Conselho da Justiça Federal. Disponível em: https://www.cjf.jus.br/cjf/corregedoria-da-justica-federal/centro-de-estudos-judiciarios1/publicacoes-1/jornadas-cej/EnunciadosAprovados-Jornadas-1345.pdf Acesso em: 11 set. 2020.

LISBOA, Roberto Senise. Manual de Direito Civil. Teoria Geral do Direito Civil. 5. ed. São Paulo: Saraiva, 2009. 231 p.

MONTEIRO, Washington de Barros; PINTO, Ana Cristina de Barros Monteiro França. Curso de Direito Civil. Parte Geral. 42. ed. São Paulo: Saraiva, 2009. 131 p.

RIZZARDO, Arnaldo. Parte Geral do Código Civil. 6. ed. Rio de Janeiro: Editora Forense, 2008. 247 p.

RODRIGUES, Silvio. Direito Civil. Parte geral. 34. ed. São Paulo: Saraiva, 2005. 86 p.

ROSENVALD, Nelson; DIAS, Wagner Inácio Freitas. Recompondo a função social do contrato: é possível um sistema em que a menor minoria possua uma tutela efetiva? Revista de Direito. v. 12, n.02, p. 01-18, 2 set. 2020.

TARTUCE, Flávio. Manual de Direito Civil. 10. ed. São Paulo: Editora Método, 2020. 163 p. 
VENOSA, Sílvio de Salvo. Direito Civil. Parte Geral. 15. ed. São Paulo: Editora Atlas, 2015. $245 \mathrm{p}$.

WALD, Arnoldo. Direito Civil. Introdução e Parte Geral. 11. ed. São Paulo: Saraiva, 2009. $185 \mathrm{p}$. 